\title{
Problems and Challenges for Reproductive Health of a Women in the $21^{\text {st }}$ Century
}

\section{Ostapiuk L $\mathbf{L}^{1,2 *}$}

${ }^{1}$ Department of Obstetrics and Gynaecology, Vinnytsia National Medical University of the Ministry of Health of Ukraine, Ukraine

${ }^{2}$ Lviv Regional Centre of Public Health, Lviv, Ukraine

*Corresponding Author: Ostapiuk Lesia, Vinnytsia National Medical University of the Ministry of Health of Ukraine, Lviv Regional Centre of Public Health, Lviv, Ukraine.
Received: March 02, 2020

Published: March 20, 2020

(C) All rights are reserved by Ostapiuk L.
As defined by the World Health Organization (WHO), reproductive health is a state of physical, mental and social well-beign. It characterizes the ability to conceive and to bear children, the possibility of sexual intercourse without the risk of sexually transmitted infections, the possibility of safe pregnancy, childbirth, survival, health and well-being of the mother, the ability to plan subsequent pregnancies and to prevent unwanted pregnancy. In order to ensure good reproductive health for women, it is necessary to take care of their health since their pre-natal development, childhood and adolescence.

The $21^{\text {st }}$ century is a period of new diagnostic opportunities, in particular in molecular biology. They allow to identify certain genetic mutations in humans and their tendency to develop certain pathological conditions. Such successful studies open the way to the development of personal medicine with an individual assessment of the prognosis of the risk of developing various diseases for each patient. Epigenetics is actively developing nowadays. It gives possibilities to investigate the functioning of genes, that can provide health or disease. In response to external influence (nutrition, emotional stress, physical activity), the activity of certain genes may increase or decrease. It is interesting to note, that woman's malnutrition during pregnancy may lead to the risk development of metabolic syndrome, obesity and type II diabetes in her child's at later stages of life. Modern diagnostic methods are being actively implemented, including the identification of different markers. Particularly promising is the use of physical methods of investigation (electron paramagnetic resonance, laser speckle rheology, fluorescence spectroscopy). In particular, the method of fluorescence spectroscopy allows to record the "effective" concentration of albu$\min$ [1], which is reduced in purulent-inflammatory diseases and in sepsis and cannot be registered by other methods, currently used in healthcare institutions. But it is important strategic indicator for the early diagnosis of sepsis before the onset of clinical manifestations [2]. Also the method of fluorescence spectroscopy allows to monitor the condition of patients and to control the treatment process according to modern principles of personal medicine [2].
At the same time, despite the new current possibilities in medical practice, the problems of pregnancy miscarriage, maternal morbidity and mortality are extremely urgent. This is largely due to the planning of pregnancy in women in late reproductive age with comorbid pathology. Such women often have a number of diseases that complicate each other. Often, a combination of extragenital pathology and complicated pregnancy is common, which leads to the complicated childbirth and often requires surgical delivery. In the postpartum period after surgical delivery there is also a high risk of complications, in particular purulent-inflammatory diseases.

However, current medical achievements allow to develop effective prevention programs, that assess the individual risk of possible complications during pregnancy, childbirth and in postpartum period for each patient. Thus, individual recommendations for the prevention of possible complications and treatment, if necessary should be prescribed. This allows women to be observed according to the principle of case management and personal medicine. Certainly, the successful implementation of this approach requires the use of statistical methods of the research. One of these is the logistic regression method, which has been used effectively in many medical studies. In particular, in our studies we used it to develop a prognostic model for the development of postpartum purulentinflammatory diseases [3]. For the convenience of using statistical methods for healthcare professionals in clinical practice, it is advisable to create online calculators to calculate individual risks for each patient according to the parameters. Thus, for each woman it is necessary to make a personal plan of pregnancy management considering her individual characteristics, anamnesis, data, lifestyles. This conceptualization is necessary at the present stage, in the period of low childbirth rates and planning pregnancy at the late reproductive age in women in high-income countries.

This approach should be used both in the postpartum period and throughout the later life of women. This enables women to realize themselves in responsible parenthood, to preserve their reproductive health and to ensure good health for future genera- 
tions. Thus, women's reproductive health status in the $21^{\text {st }}$ century should be controlled from the beginning of their prenatal period until their birth and the later life.

\section{Bibliography}

1. Grizunov YA., et al. "Serum Albumin in Clinical Medicine". Moscow Geotar (1998): 440.

2. Ostapiuk L. "Diagnostic and Therapeutic Model of Sepsis and Purulent-Inflammatory Diseases". International Journal of Clinical Medicine 10 (2019): 577-595.

3. Bulavenko 0., et al. "A Prognostic Model of the Development of Postpartum Purulent-Inflammatory Diseases". International Journal of Clinical Medicine 11 (2020): 32-42.

\section{Assets from publication with us}

- Prompt Acknowledgement after receiving the article

- Thorough Double blinded peer review

- Rapid Publication

- Issue of Publication Certificate

- High visibility of your Published work

Website: www.actascientific.com/

Submit Article: www.actascientific.com/submission.php

Email us: editor@actascientific.com

Contact us: +919182824667 